\title{
Application of Aramid Nanofibers in Nanocomposites: A Brief Review
}

\author{
Yangyang Fan ${ }^{1,2,3}$, Zhihua $\mathrm{Li}^{1,2, *}$ and Junchao Wei ${ }^{1,2,3, *}$ \\ 1 School of Stomatology, Nanchang University, Nanchang 330006, China; Fanyy16655285545@163.com \\ 2 Jiangxi Province Key Laboratory of Oral Biomedicine, Nanchang 330006, China \\ 3 College of Chemistry, Nanchang University, Nanchang 330031, China \\ * Correspondence: lizhihua@ncu.edu.cn (Z.L.); weijunchao@ncu.edu.cn (J.W.); Tel.: +86-791-863-603-98 (J.W.)
}

check for

updates

Citation: Fan, Y.; Li, Z.; Wei, J.

Application of Aramid Nanofibers in

Nanocomposites: A Brief Review.

Polymers 2021, 13, 3071 .

https://doi.org/

$10.3390 /$ polym13183071

Academic Editor: Wael Mamdouh

Received: 3 August 2021

Accepted: 6 September 2021

Published: 11 September 2021

Publisher's Note: MDPI stays neutral with regard to jurisdictional claims in published maps and institutional affiliations.

Copyright: (c) 2021 by the authors. Licensee MDPI, Basel, Switzerland. This article is an open access article distributed under the terms and conditions of the Creative Commons Attribution (CC BY) license (https:// creativecommons.org/licenses/by/ $4.0 /)$.

\begin{abstract}
The diameter of fibers is a critical factor in determining their final applications. When the diameter of aramid fibers changes from microns to nanoscale, its range of applications will be greatly extended. In this short review, the preparation of aramid nanofibers (ANFs) with diameters from ten nanometers to more than one hundred nanometers is introduced. Due to their excellent mechanical properties and their chemical and thermal stability, ANFs have been widely used as novel nanomaterials and composited with other materials, mainly for use in reinforced composites, energy storage, filtration and adsorption, biomedicine and electromagnetic fields. In this short review, the application of ANFs and their composites during the last 10 years is concisely summarized and a brief perspective on ANFs and their composites is also presented.
\end{abstract}

Keywords: aramid nanofiber; composite materials; blend; mechanical properties

\section{Introduction}

Aramid fiber is a kind of aromatic polyamide fiber that possesses high temperature resistance, chemical corrosion resistance, fatigue resistance and super mechanical properties. For example, Kevlar fiber, which is made from para-aramid, has excellent mechanical properties, its tensile strength can reach about 3.6 GPa, and its modulus can reach about $120 \mathrm{GPa}$; thus, it has been widely used in the aerospace, military protection, the automotive industry and sporting goods fields [1-3]. Generally, the diameter of aramid fiber ranges from several to approximately ten microns [4]. The diameter of fibers may be a critical factor affecting its properties and final applications. Reducing the diameter of aramid fibers to a nanoscale may bring some excellent new properties, and the nanofibers may also work as fillers to blend with other materials and prepare functional composites. Great efforts have therefore been made to develop aramid nanofibers (ANFs).

Electrospinning is an efficient method to prepare various nanofibers and has been widely used in drug delivery and tissue engineering, amongst other applications [5]. However, a critical factor that can affect electrospinning is the solubility of electrospun materials. As for aramid fiber, due to the high crystallinity of aramid fibers and the strong hydrogen bonds between aramid molecules, it is much more difficult to prepare ANFs via the electrospinning method. Nevertheless, Yang's group designed a top-down method with aramid fibers as the raw materials, dissolving them in dimethyl acetamide with $\mathrm{LiCl}$ to form an electrospinning solution, and obtained electrospun ANFs therefrom. However, in this experiment, a high temperature was required, and the diameters of fibers were about 69 to $180 \mathrm{~nm}$ [4]. Tuo's group, by contrast, prepared ANFs via a bottom-up method, which used the polymerization of terephthaloyl chloride and p-phenylene diamine; meanwhile, methoxypolyethylene glycol (mPEG) was added during the polymerization process-an addition that can suppress the aggregation of liquid-crystal polymers in polyaramid chains. ANFs were then prepared by intensive shear and precipitating agents [6]. In 2011, Kotov used $\mathrm{KOH}$ and DMSO deprotonation methods to peel Kevlar fibers and obtained aramid 
nanofibers (ANFs) with a diameter of 5-30 nm and a length of 5-10 $\mu \mathrm{m}$ [7]. However, there were some drawbacks, such as low concentration, low efficiency and time consumption. Therefore, it is still a great challenge and of great importance to design new methods to obtain ANFs.

ANFs possess a high specific surface area and high aspect ratio and have shown excellent mechanical and stability properties. They have been widely used as novel nano-building blocks to prepare high strength films, aerogels and other functional materials [8-10]. In addition, ANFs can also be used as nano-fillers to blend with a variety of materials, such as polyvinyl alcohol (PVA) [11,12], polyurethane (PU) [13], polyacrylic acid (PAA) [14], polyethylene glycol (PEO) [15-17], carbon nanotubes (CNT) [18,19], graphene oxide (GO) [20-23], boron nitride nanosheets (BNNS) [24,25] and epoxy [26]. Previous work has demonstrated that ANFs and their nanocomposites have great potential applications in many fields [27-29], such as high-strength composites, energy storage, adsorption and filtration, biomedicine and electromagnetic fields.

In this short review, we briefly summarize the application of ANFs and their composites before discussing their existing problems and prospects. In drawing attention to the current state of research, we hope to generate interest and stimulate further work on ANFs so that they can be put to use in our daily life.

\section{Application of Aramid Nanofibers}

\subsection{High-Strength Nanocomposites}

Mechanical properties are the key factors that limit the application of composites. Improvements are restricted by nano-fillers and the interaction between nano-fillers and the polymer matrix. Hydrogen bonds and $\pi-\pi$ interactions are easily formed between ANF molecular chains and other molecules, which can effectively enhance the interfacial adhesion between ANFs and matrix materials. Therefore, ANFs can be used as nano-filler to prepare nanocomposites with excellent mechanical strength and toughness. For example, PVA has been blended with ANFs and to effectively improve its mechanical properties. Guan [11] et al. prepared PVA/ANF composite membranes by a simple solution casting method (Figure 1A). The Young's modulus of the film was $5.2 \mathrm{GPa}, 18.2 \%$ higher than that of pure PVA film, and the tensile strength and toughness were, respectively, $79.2 \%$ and $148.8 \%$ higher than that of PVA. Kotov [12] et al. prepared a biomimetic PVA/ANF hydrogel with water content of $70-92 \%$, and the tensile modulus, ultimate tensile strain, compressive strength and fracture toughness of the hydrogel reached $9.1 \mathrm{MPa}, 325 \%, 26 \mathrm{MPa}$ and $9200 \mathrm{~J} / \mathrm{m}^{2}$, respectively. Yang [13] et al. used ANFs to reinforce polyurethane (PU), another kind of widely used polymer. Due to the multiple hydrogen bonding between ANFs and PU molecules, the mechanical properties of the PU/ANF composite were much better than those of PU, and its strength and Young's modulus were $98.02 \mathrm{MPa}$ and $5.275 \pm 0.548 \mathrm{GPa}$, respectively. Kotov [14] et al. also prepared ANF/PAA (polyacrylic acid) composite films by a vacuum-assisted filtration method. When PAA content was $20 \%$, the modulus of the film reached about $20 \mathrm{GPa}$.

The dispersion of nanofillers is one of the key factors influencing the properties of the composite material. The surface treatment of ANFs helps to improve its dispersion state and thus may improve its reinforcement effect. For example, polysulfone (PSU) was grafted onto an ANF surface via in situ $S_{N} A r$ polymerization (Figure 1B), which maximized the dispersion of ANFs in the PSU matrix. Furthermore, only $0.15 \mathrm{wt}$. \% nanofiller can make the tensile strength and toughness of PSU composites 1.6 times and 3.4 times higher than those of neat PSU, respectively [30]. ANFs can also be used to modify other components. For example, carbon nanotubes can be coated with ANFs by anodic electrophoresis, which can improve the bonding strength between carbon nanotubes and the epoxy matrix [31]. Park [32] et al. assembled ANFs and graphene oxide layers on the glass fiber, which improved the surface free energy and interfacial shear strength compared with those of the bare glass fiber (Figure 2). The interfacial adhesion interactions are highly adjustable and can be altered by changing the composition and structure of the coating. 


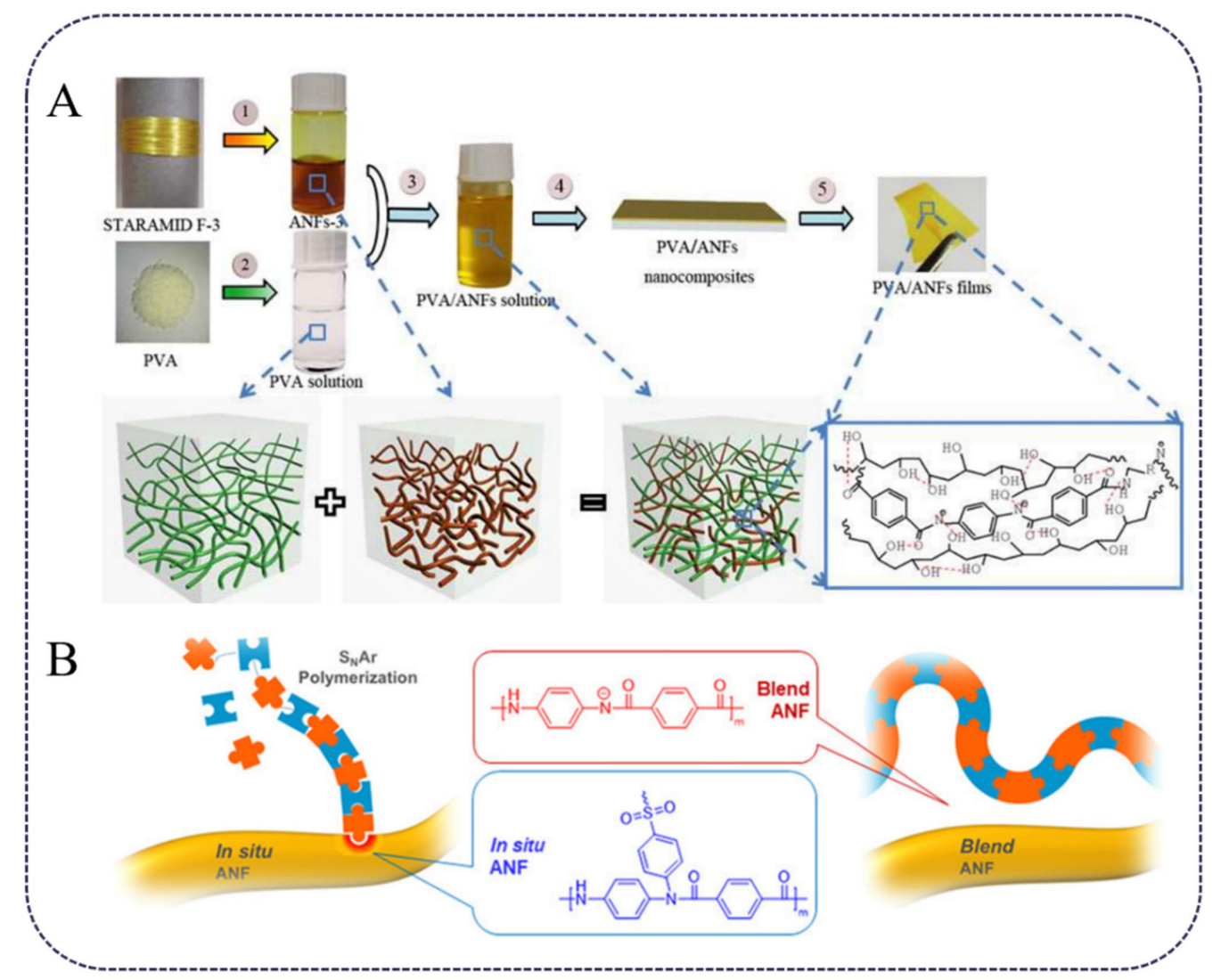

Figure 1. (A) Schematic illustration of interactions between PVA and ANFs via a simple solution casting method [11] (Copyright 2017 Elsevier). (B) Schematic illustration of the nanocomposite preparation by in situ and blending methods [30] (Copyright 2020, American Chemical Society).
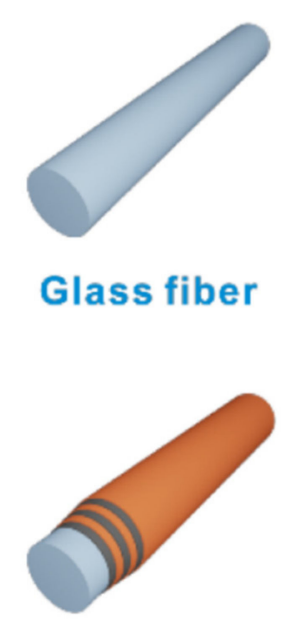
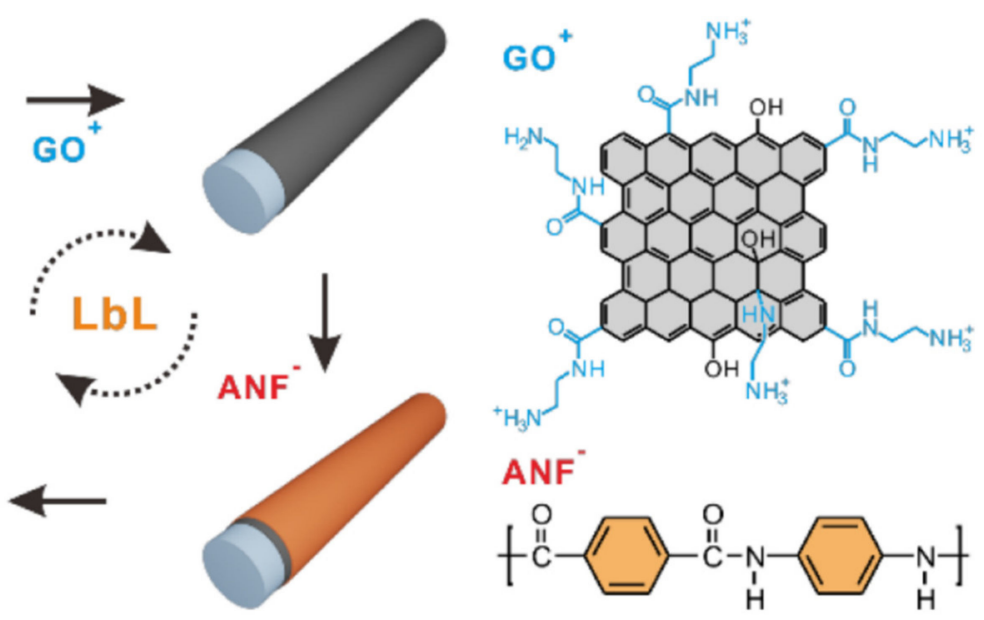

Figure 2. Schematic of the preparation of a positively charged graphene oxide (GO) and negatively charged aramid nanofiber (ANF) multilayer coating on a glass fiber via nanoscale blending layer-by-layer (LBL) assembly [32] (Copyright 2015, American Chemical Society).

By combining ANFs with different materials, composites with both strong mechanical properties and different functions can be obtained. The high mechanical strength lays the foundation for the application of composite materials in a variety of different environments, 
which gives ANF composites a bright application prospect in energy storage, adsorption filtration and biomedical applications, amongst other things.

\subsection{Energy Storage}

Energy storage has been a hot topic all over the world, but the insufficient performance of energy storage materials has limited the development of energy storage equipment. Over recent years, ANFs have been combined with energy storage materials to obtain strong materials that can be used as battery separators, solid electrolytes and electrode materials.

Lithium-ion batteries are important energy storage devices, but there are still some safety issues, such as dendrites piercing the separator. Therefore, tuning the properties of the separator is an efficient method for improving the safety of lithium batteries. In 2015, Kotov [16] et al. prepared ANF/PEO (polyethylene oxide) ion-conducting membranes via the layer-by-layer (LbL) method. When (PEO/ANF) 200 film (the number 200 represents the deposition cycles of LBL) as thin as $3 \mu \mathrm{m}$ was used, the performance was comparable to that of commercial Celgard film with a thickness at least of $25 \mu \mathrm{m}$. Wang et al. [33] prepared an ANF/polyphenylene sulfide nonwoven composite separator, and ANFs regulated the porosity and enhanced electrolyte absorption of the film, resulting in better interfacial compatibility and superior ionic conductivity. ANFs can also be used in solid composite polymer electrolytes. ANF/PEO-LiTFSI (lithium bis(trifluoromethylsulfonyl)imide) composite polymer electrolytes (CPEs) can be obtained by solution casting method [34]. The hydrogen bond interaction between ANFs, PEO and LiTFSI can induce CPEs to form a 3D network, providing a place for the dissociation of LiTFSI and leading to the enhancement of electrochemical, mechanical and thermal stability. Zinc batteries have greater energy density and availability than lithium-ion batteries, but archetypal zinc batteries have the disadvantages of being inflexible, non-rechargeable and containing corrosive electrolytes. On the basis of research on lithium batteries, the development of solid electrolytes for $\mathrm{Zn}$ batteries seems to be an appropriate way to overcome the shortcomings. Kotov et al. [17] prepared a solid electrolyte of $\mathrm{PEO} / \mathrm{Zn}\left(\mathrm{CF}_{3} \mathrm{SO}_{3}\right)_{2}$ / BANFS (PZB) by adding $\mathrm{Zn}\left(\mathrm{CF}_{3} \mathrm{SO}_{3}\right)_{2}$ into the PEO/ANF network. The zinc battery made of PZB has a charging capacity and maintains coulomb efficiency of $96-100 \%$ after 50-100 charge-discharge cycles. The bionic solid electrolyte enables the battery to withstand elastic and even plastic deformation and makes the application of distributed capacitors possible (Figure 3A).

ANFs can be used to improve the mechanical and cycling properties of electrode materials. For example, (poly(3,4-ethylenedioxythiophene):poly(styrene sulfonate) (PEDOT:PSS) is a promising electrode materials; however, its low mechanical properties have limited its application. When ANFs were combined with PEDOT:PSS, a strong and flexible composite membrane ANF/PEDOT:PSS was prepared by vacuum filtration. Under bending and torsion conditions, the electrical conductivity of the composite film can still reach $534.2 \mathrm{~S} \cdot \mathrm{cm}^{-1}$ [35]. In addition, ANFs and polyaniline (PANI) were also used to fabricate flexible electrode materials. The energy storage and mechanical properties are achievable by adjusting the polymerization of PANI on an ANF substrate [36]. In 2017, a novel ANF/GO electrode was fabricated via the LBL method [22]. The chemically reduced electrodes exhibited capacitive charge storage with areal capacitances as high as $221 \mu \mathrm{F} / \mathrm{cm}^{2}\left(78 \mathrm{~F} / \mathrm{cm}^{3}\right)$ in the battery test. Therefore, both mechanical and electrochemical properties can be fully manipulated. The GO hydrogel electrode is a kind of graphene electrode material, which has a high specific surface area and high porosity, so it is widely used as a binder-free electrode for supercapacitors. However, its 3D architectures tend to have poor mechanical integrity. To solve this problem, in 2019, Micah J. Green's group [23] fabricated an ANF/GO composite hydrogel electrode. Due to hydrogen bonds and $\pi-\pi$ stack interactions between ANFs and GO, the shear modulus of the composite hydrogel with only $2 \%$ ANFs increased by $80 \%$ that of the GO hydrogel (Figure 3B). 


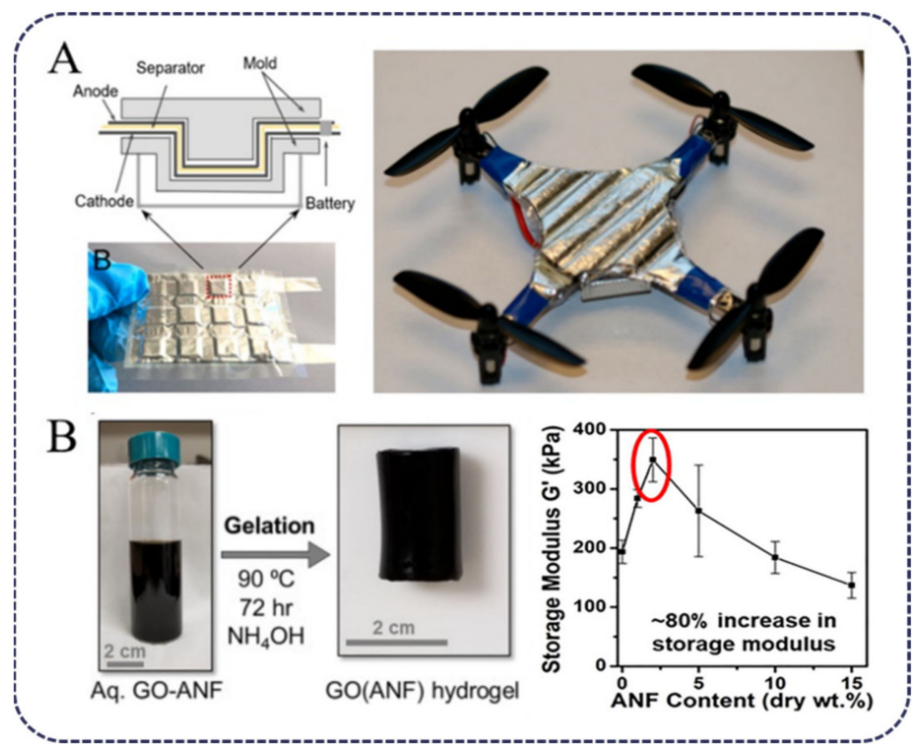

Figure 3. (A) Schematic of the mold used for plastic deformation studies and deformed shapes of Zn battery with solid-state biomimetic electrolyte PZB-931 for UAV [17] (Copyright 2019, American Chemical Society). (B) Sol-gel gelation results in formation of a GO(ANFx) hydrogel and comparison of storage modulus ( $\left.\mathrm{G}^{\prime}\right)$ for all ANF loadings [23] (Copyright 2019, Elsevier).

The introduction of ANFs with their high strength, corrosion resistance and high temperature resistance helps to eliminate the performance defects in energy storage materials. By simply adjusting the composition of the composite, a balance of mechanical and electrical properties of materials can be obtained, which provides a new possibility for the further development and practical application of energy storage equipment.

\subsection{Adsorption and Filtration}

With the rapid development of industry, water pollution has been a serious problem. Wastewater contains various harmful impurities, such as heavy metal ions and organic dyes, which cause serious harm to the biological and natural environment. Adsorption and filtration are commonly used methods for wastewater treatment, and, thus, various types of materials, such as fiber, membrane and aerogel, have been designed to treat polluted water [37-39]. ANFs, as an important polymer material, showed a high solvent tolerance and are an efficient candidate for water treatment. Wu et al. [40] prepared a metal-organic framework (MOF) incorporated with ANF aerogel and obtained a mixed aerogel (Figure 4), which exhibited superior adsorption performance for organic dyes from aqueous solution efficiently and continuously (e.g., $113.8 \mathrm{mg} / \mathrm{g}$ for methyl violet and $107 \mathrm{mg} / \mathrm{g}$ of rhodamine $\mathrm{B}$, high flux $\left(620 \mathrm{~L} /\left(\mathrm{h} \cdot \mathrm{m}^{2} \cdot\right.\right.$ bar $)$ at a thickness of $\left.\sim 0.87 \mathrm{~mm}\right)$. In addition, ANFs with special functional groups can also be used to detect metal ions in water via the special absorption ability of ANFs with respect to metal ions. For example, benzimidazole-containing ANF (B-ANF) can induce aggregation of many heavy metal ions $\left(\mathrm{Fe}^{3+}, \mathrm{Ni}^{2+}, \mathrm{Cu}^{2+}, \mathrm{Mn}^{2+}, \mathrm{Ag}^{+}\right.$, $\mathrm{Fe}^{2+}, \mathrm{Hg}^{2+}, \mathrm{Pd}^{2+}$ and $\mathrm{Cd}^{2+}$ ) [41], which can be detected by the naked eye, implying that B-ANF can be used as a promising detector for metal ions in the future.

The filtration membrane plays an important role in industrial production and daily life. Good solvent resistance and mechanical strength are the necessary requirements for filtration membranes. ANF-based membranes with good mechanical properties and stability show great potential as filtration membranes. For example, when ANFs are used to coat the surface of a poly(ethylene terephthalate) (PET) non-woven membrane, the mechanical properties of the PET membranes can be improved and the composite membrane can work as an ultrafiltration membrane, realizing the removal of Au nanoparticles $(10 \mathrm{~nm})$ from solution with a rejection rate above $90 \%$ [42]. Additionally, ANFs can be incorporated into or mixed with many other polymers to prepare filtration membranes [43]. When 
ANFs were incorporated with silk fibers, the hybrid films showed an ultimate stress and Young's modulus two times that of the pure silk film, enabling potential applications such as pressure-driven nanofiltration. By mixing PEI with ANF casting solution, a high-flux organic solvent nanofiltration membrane was fabricated by Bart et al. [44]. The membrane has a permeability more than 4 times higher than that of an ANF membrane. After 6 days of methanol treatment, the highest ethanol permeability was $9.1 \mathrm{~L} \mathrm{~m}^{-2} \mathrm{~h}^{-1} \mathrm{bar}^{-1}$ and showed a high rejection rate of rose Bengal (RB).

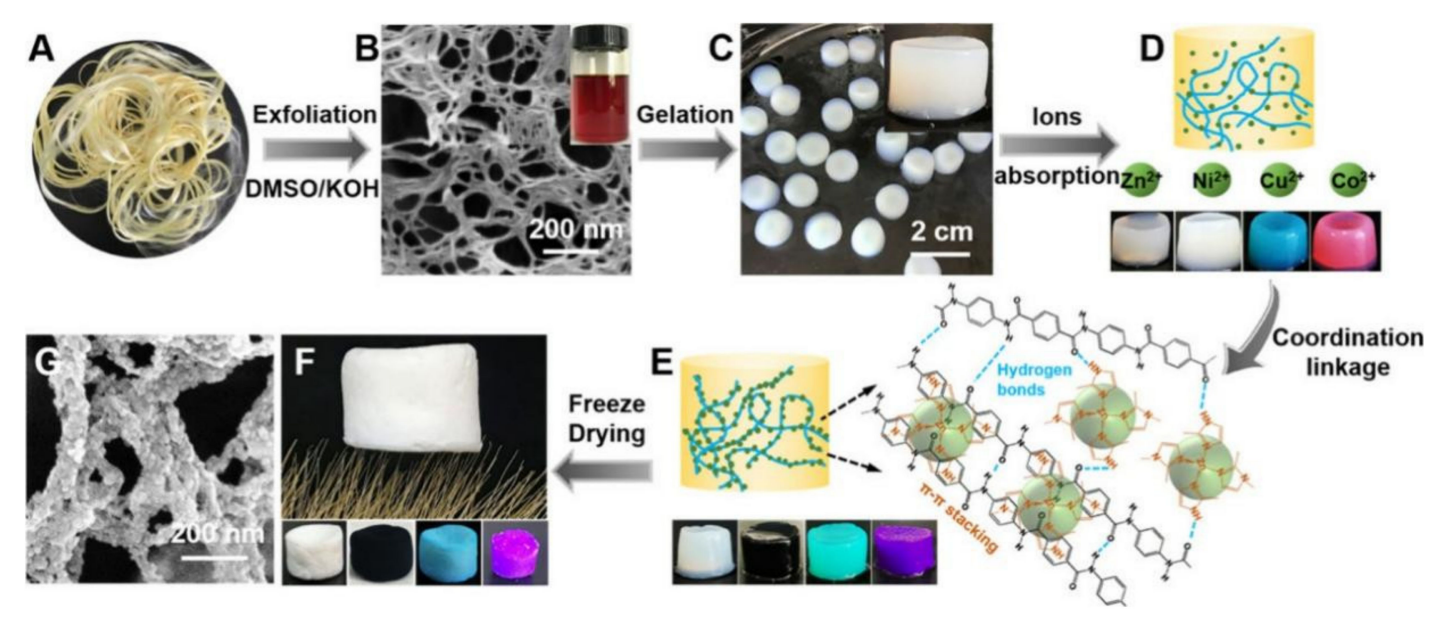

Figure 4. Pathway followed to fabricate MOF hybrid aerogels [40] (Copyright 2020, American Chemical Society).

\subsection{Biomedical Application}

The removal of metabolites and toxins in blood is still a major challenge for modern medicine. The problems of low efficiency, poor blood compatibility and easy pollution of blood purification materials need to be solved [45,46]. ANF composites have been used for blood purification because of their large surface area, controllable surface function, high porosity and great hydrophilicity. According to Zhao's work [47], ANF beads prepared by dissolving micron-sized Kevlar fibers in proper solvent that showed good blood compatibility and low cytotoxicity, possessed an adsorption capacity higher than $40 \mathrm{mg} \mathrm{g}^{-1}$ towards bilirubin. Furthermore, beads with the addition of carbon nanotubes showed a stronger ability to adsorb human degradation waste.

ANFs are used to improve the biological and filtration properties of other polymer membranes. For example, polysulfon (PSF) and polyether sulfone (PES) are commonly used as ultrafiltration membranes in medicine, but they are often contaminated by the adhesion of proteins and organisms [48]. Due to the addition of ANFs, the membranes had higher water fluxes and retained high BSA rejection ratios compared to their pristine counterparts. ANF-modified membranes also show improved blood compatibility, and, furthermore, the blending of ANFs improved the efficiency of the composite membranes in removing creatinine toxins (Figure 5). In addition, ANFs have been shown to have potential in the development of load-bearing biomaterials [12]. The biomimetic hydrogels fabricated by aramid nanofibers interlacing with poly(vinyl alcohol), with water contents of as high as $70-92 \%$, meanwhile, due to their excellent mechanical strength, match or exceed those of prototype tissues, e.g., cartilage. 


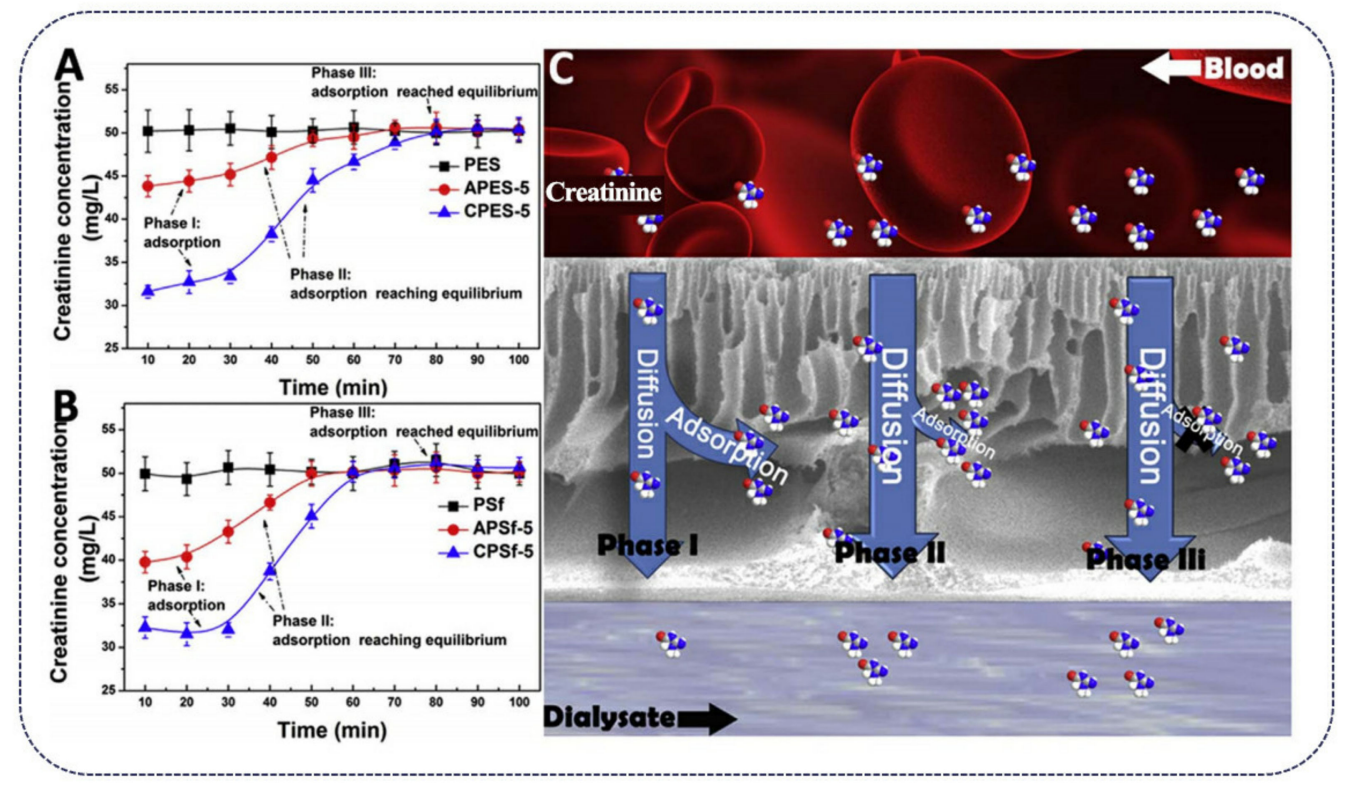

Figure 5. (A,B) Creatinine concentrations in the filtrate during the ultrafiltration by using PES- and PSF-based membranes, respectively. (C) Schematic image depicting the adsorption and diffusion of creatinine during ultrafiltration [48] (Copyright 2017, Elsevier).

\subsection{Electromagnetics Applications}

Compared with metallic materials, electrically conductive polymer composites, with the characteristics of lightweight resistance to corrosion and easy processing, have been widely used as electric heating materials [49]. Composites composed of ANFs and conductive materials usually show excellent abilities to convert electric energy into heat energy. For example, ANFs were used to fabricate nanocomposite papers with Ag nanowires (AgNWs) by vacuum-assisted filtration followed by a hot-pressing approach [50]. The heating temperature of electrical heaters containing $0.5 \mathrm{~g} / \mathrm{m}^{2}$ AgNWs can be stabilized above $200{ }^{\circ} \mathrm{C}$ at $2.5 \mathrm{~V}$. Furthermore, for materials with a conductive network, good conductivity is often accompanied by excellent electromagnetic interference (EMI) shielding performance. Examples include composites prepared by ANFs and CNT [51], polyaniline (PANI) [52] and Mxene [53]. For example, hydrated aramid nanofiber (HANF) can be mixed with expanded graphite (EG); moreover, $10 \mathrm{wt}$. \% HANF can endow EG films with good flexibility, and the EMI shielding property of EG film reached $34.9 \mathrm{~dB}$ at the thickness of $30 \mu \mathrm{m}$ [54].

As modern electrical equipment is gradually becoming miniaturized and high powered, dielectric materials with excellent mechanical properties and dielectric properties are indispensable [55]. ANFs were combined with some inorganic materials, such as montmorillonite [56] and BNNs [57], to prepare composites for electrical insulating material. A bioinspired ultra-tough multifunctional mica-based nanopaper containing a 3D aramid nanofiber framework has been reported [58]. The high dielectric strength $\left(164 \mathrm{kV} \mathrm{mm}^{-1}\right)$, excellent heat resistance $\left(\mathrm{Tg}=268^{\circ} \mathrm{C}\right)$ and nonflammability render the mica-based nanopaper a promising electrical insulating material in miniaturized highpower electrical equipment.

\subsection{Other Applications}

ANF composites can also be used for thermal insulation, heat conduction and heat dissipation. For example, ANFs can be directly made into aerogels with low density and low thermal conductivity, which can be further combined with phase change composites (PCM) to obtain ANF/PCM composites, such as the aerogel film with excellent thermal insulation performance that demonstrated high performance in military infrared stealth $[59,60]$. High temperature stability makes ANFs an ideal strengthening component of thermal 
conductivity composites. By combining them with BNNs [61,62], high-strength and highthermal conductivity composites can be obtained, which can be used for heat dissipation in high-speed communication equipment and high-power devices. The combination of conducting polymers endowing ANFs with high electric conductivity and the responsivity of conductivity to different stimuli (human motions, spoken words and environmental humidity variation) means that ANF nanocomposites show great potential for applications in, for example, sensing garments, wearable hardware and rehabilitation [63].

\section{Conclusions and Prospects}

ANFs, as a new kind of nano building block, possess many advantages, such as excellent mechanical properties, high chemical corrosion resistance and thermal stability. In this short review, the applications of ANFs in high-strength composites, energy storage, filtration and adsorption, biomedical fields, amongst other fields, were briefly summarized, and some special properties of ANFs and their composites are listed in Table 1. Excluding the merits of mechanical properties, the prepared ANF composites also showed very good electrical conductivity, superior adsorption performance, EMI shielding and many other exciting properties, implying that ANFs will have a bright prospect in the next few years. However, the applications of ANFs are still in an early stage, and there is a long way to go before putting ANFs to practical use.

Due to their impressive properties, in the next few years, the research into ANFs is expected to attract an increasing amount of attention. It should be noted that the present method used to prepare ANFs is time consuming and cannot realize its production on a macro-scale. Thus, simple and efficient methods to prepare ANFs on such a scale should be proposed so as to enable wider applications. Secondly, phase compatibility is a critical factor for nanocomposites, and, thus, the surface treatment or surface tailoring of ANFs is also an interesting topic, exploration of which may greatly improve the properties of ANF composites. In addition, advanced functional materials being a goal of researchers, ANFbased functional materials for use in special fields make attractive research subjects, and we are sure that an increasing number of materials composed of ANFs will be developed and will be found to show potential applications in emerging fields, such as intelligent sensing, flexible wearable devices and biomedical fields. 
Table 1. Application of ANF composites.

\begin{tabular}{|c|c|c|c|c|}
\hline General Application Fields & $\begin{array}{l}\text { Other Composites } \\
\text { Component }\end{array}$ & Practical Application Prospect & Key Properties & Ref. \\
\hline \multirow{4}{*}{ High-strength nanocomposites } & PVA & Fuel cells, water desalination units; batteries; filters & $\begin{array}{l}\text { Water content }(70-92 \%) \text {; tensile moduli } \approx 9.1 \mathrm{MPa} \\
\text { ultimate tensile strains } \approx 325 \% \text {; compressive } \\
\text { strengths } \approx 26 \mathrm{MPa}\end{array}$ & [12] \\
\hline & PU & High-strength nanocomposites & Modulus (5.275 GPa); strength (98.02 MPa) & [13] \\
\hline & PSU & Engineering plastics & Tensile strength $(79 \mathrm{MPa})$ & [30] \\
\hline & PEO & Ion-conducting membranes & Ionic conductivity $\left(1.7 \times 10^{-4} \mathrm{~S} \cdot \mathrm{cm}^{-1}\right)$ & {$[16]$} \\
\hline \multirow{5}{*}{ Energy storage } & GO & Supercapacitor electrodes & Areal capacitance $\left(221 \mu \mathrm{F} / \mathrm{cm}^{2}\right)$ & [22] \\
\hline & GO & Supercapacitor electrodes & Specific capacitance $(128 \mathrm{~F} / \mathrm{g})$ & {$[23]$} \\
\hline & PEDOT:PSS & Supercapacitor electrode & $\begin{array}{l}\text { Electrical conductivity }\left(534.2 \mathrm{~S} \cdot \mathrm{cm}^{-1}\right) \text {; a specific } \\
\text { capacitance }\left(111.5 \mathrm{~F} / \mathrm{g} \text { at } 0.5 \mathrm{~A} \cdot \mathrm{cm}^{-3}\right)\end{array}$ & [35] \\
\hline & PANI & Supercapacitor electrode & Specific capacitance $(441.0 \mathrm{~F} / \mathrm{g}$ at $1 \mathrm{~A} / \mathrm{g})$ & [36] \\
\hline & MOF & Mechanically strong MOF hybrid aerogels & $\begin{array}{l}\text { Superior adsorption performance for organic dyes; } \\
\text { high flux }\left(620 \mathrm{~L} /\left(\mathrm{h} \cdot \mathrm{m}^{2} \cdot \mathrm{bar}\right)\right)\end{array}$ & {$[40]$} \\
\hline \multirow{2}{*}{ Adsorption and filtration } & Benzimidazole & Recyclable detector for heavy metal ions & Fast detection of heavy metal ions & [41] \\
\hline & PEI & Organic solvent nanofiltration & $\begin{array}{c}\text { Ethanol flux }\left(9.1 \mathrm{~L} \mathrm{~m}^{-2} \mathrm{~h}^{-1} \mathrm{bar}^{-1}\right) \text {; high RB rejection } \\
\text { of } 98.4 \%\end{array}$ & [44] \\
\hline Biomedical application & PSF; PES & Water purification and clinical hemodialysis & $\begin{array}{l}\text { Antifouling; good blood compatibility; remove } \\
\text { creatinine toxin }\end{array}$ & [48] \\
\hline \multirow{5}{*}{ Electromagnetics applications } & CNT & $\begin{array}{l}\text { Wearable electronics; EMI shielding clothing; } \\
\text { personal thermal management systems }\end{array}$ & $\begin{array}{l}\text { Electrical conductivity }\left(230 \mathrm{~S} \cdot \mathrm{m}^{-1}\right) \text {; EMI shielding } \\
\text { property }(54.4 \mathrm{~dB} \text { at thickness of } 568 \mu \mathrm{m})\end{array}$ & [51] \\
\hline & Mxene & Flexible electronic devices and wearable equipment & Specific EMI shielding property $\left(8814.5 \mathrm{~dB} \cdot \mathrm{cm}^{2} \cdot \mathrm{g}^{-1}\right)$. & [53] \\
\hline & EG & Smart phones and flexible electronic devices & $\begin{array}{l}\text { Electrical conductivity }\left(215 \mathrm{~S} \cdot \mathrm{cm}^{-1}\right) \text {; EMI shielding } \\
\text { property }(34.9 \mathrm{~dB} \text {, at thickness of } 30 \mu \mathrm{m})\end{array}$ & {$[54]$} \\
\hline & Montmorillonite & Flexible electronics; high-voltage electrical insulation & Dielectric insulation performance $(77.2 \mathrm{kV} / \mathrm{mm})$ & [56] \\
\hline & BNNS & $\begin{array}{l}\text { Flexible electronics; energy storage; high-temperature } \\
\text { electric power devices }\end{array}$ & $\begin{array}{l}\text { Electrically insulating }(>1015 \Omega \mathrm{cm}) \text {; thermally } \\
\text { conductive }\left(\approx 2.4 \mathrm{~W} \cdot \mathrm{m}^{-1} \cdot \mathrm{K}^{-1}\right) \text {; breakdown strength } \\
\left(\approx 292 \mathrm{MV} \cdot \mathrm{m}^{-1}\right)\end{array}$ & [57] \\
\hline Others & $\begin{array}{l}\text { Phase-change materials } \\
\text { Polypyrrole }\end{array}$ & $\begin{array}{l}\text { Infrared stealth } \\
\text { Strain and humidity sensors }\end{array}$ & $\begin{array}{l}\text { Thermal conductivity }\left(0.036 \mathrm{~W} \cdot \mathrm{m}^{-1} \cdot \mathrm{K}^{-1}\right) \\
\text { Electric conductivity up to } \sim 25 \mathrm{~S} \mathrm{~m}^{-1}\end{array}$ & $\begin{array}{l}{[60]} \\
{[63]}\end{array}$ \\
\hline
\end{tabular}


Author Contributions: Conceptualization, J.W. and Z.L.; methodology, Y.F.; resources, Z.L.; writingoriginal draft preparation, Y.F.; writing-review and editing, J.W. and Z.L.; supervision, J.W.; project administration, J.W.; funding acquisition, J.W. All authors have read and agreed to the published version of the manuscript.

Funding: The project was supported by Jiangxi Key Research and Development Program (NO.20202BBG73012), National Natural Science Foundation of China (No. 52163016).

Institutional Review Board Statement: Not applicable.

Informed Consent Statement: Not applicable.

Data Availability Statement: The data presented in this study are available on request from the corresponding author.

Conflicts of Interest: The authors declare no conflict of interest.

\section{References}

1. García, J.M.; García, F.C.; Serna, F.; de la Peña, J.L. High-performance aromatic polyamides. Prog. Polym. Sci. 2010, 35, 623-686. [CrossRef]

2. Seo, M.; Park, J.; Kim, S.Y. Self-assembly driven by an aromatic primary amide motif. Org. Biomol. Chem. 2012, 10, 5332-5342. [CrossRef]

3. Kulkarni, S.G.; Gao, X.L.; Horner, S.E.; Zheng, J.Q.; David, N.V. Ballistic helmets-Their design, materials, and performance against traumatic brain injury. Compos. Struct. 2013, 101, 313-331. [CrossRef]

4. Wei, Z.; Zhang, Q.; Wang, L.; Peng, M.; Wang, X.; Long, S.; Yang, J. The preparation and adsorption properties of electrospun aramid nanofibers. J. Polym. Sci. Part B Polym. Phys. 2012, 50, 1414-1420. [CrossRef]

5. Feng, X.; Li, J.; Zhang, X.; Liu, T.; Ding, J.; Chen, X. Electrospun polymer micro/nanofibers as pharmaceutical repositories for healthcare. J. Control. Release 2019, 302, 19-41. [CrossRef] [PubMed]

6. Li, J.; Tian, W.; Yan, H.; He, L.; Tuo, X. Preparation and performance of aramid nanofiber membrane for separator of lithium ion battery. J. Appl. Polym. Sci. 2016, 133, 43623. [CrossRef]

7. Yang, M.; Cao, K.; Sui, L.; Qi, Y.; Zhu, J.; Waas, A.; Arruda, E.M.; Kieffer, J.; Thouless, M.D.; Kotov, N.A. Dispersions of Aramid Nanofibers: A New Nanoscale Building Block. ACS Nano 2011, 5, 6945-6954. [CrossRef] [PubMed]

8. Luo, J.; Zhang, M.; Nie, J.; Liu, G.; Tan, J.; Yang, B.; Song, S.; Zhao, J.R. A deep insight into the structure and performance evolution of aramid nanofiber films induced by UV irradiation. Polym. Degrad. Stabil. 2019, 167, 170-178. [CrossRef]

9. Xie, C.; He, L.; Shi, Y.; Guo, Z.X.; Qiu, T.; Tuo, X. From Monomers to a Lasagna-like Aerogel Monolith: An Assembling Strategy for Aramid Nanofibers. ACS Nano 2019, 13, 7811-7824. [CrossRef] [PubMed]

10. Patel, A.; Wilcox, K.; Li, Z.; George, I.; Juneja, R.; Lollar, C.; Lazar, S.; Grunlan, J.; Tenhaeff, W.E.; Lutkenhaus, J.L. High Modulus, Thermally Stable, and Self-Extinguishing Aramid Nanofiber Separators. ACS Appl. Mater. Interfaces 2020, 12, 25756-25766. [CrossRef]

11. Guan, Y.; Li, W.; Zhang, Y.; Shi, Z.; Tan, J.; Wang, F.; Wang, Y. Aramid nanofibers and poly(vinyl alcohol) nanocomposites for ideal combination of strength and toughness via hydrogen bonding interactions. Compos. Sci. Technol. 2017, 144, 193-201. [CrossRef]

12. Xu, L.; Zhao, X.; Xu, C.; Kotov, N.A. Water-Rich Biomimetic Composites with Abiotic Self-Organizing Nanofiber Network. Adv. Mater. 2018, 30, 1703343. [CrossRef] [PubMed]

13. Kuang, Q.; Zhang, D.; Yu, J.C.; Chang, Y.-W.; Yue, M.; Hou, Y.; Yang, M. Toward Record-High Stiffness in Polyurethane Nanocomposites Using Aramid Nanofibers. J. Phys. Chem. C 2015, 119, 27467-27477. [CrossRef]

14. Yang, M.; Cao, K.; Yeom, B.; Thouless, M.D.; Waas, A.; Arruda, E.M.; Kotov, N.A. Aramid nanofiber-reinforced transparent nanocomposites. J. Compos. Mater. 2015, 49, 1873-1879. [CrossRef]

15. Patterson, B.A.; Malakooti, M.H.; Lin, J.; Okorom, A.; Sodano, H.A. Aramid nanofibers for multiscale fiber reinforcement of polymer composites. Compos. Sci. Technol. 2018, 161, 92-99. [CrossRef]

16. Tung, S.O.; Ho, S.; Yang, M.; Zhang, R.; Kotov, N.A. A dendrite-suppressing composite ion conductor from aramid nanofibres. Nat. Commun. 2015, 6, 6152. [CrossRef]

17. Wang, M.; Emre, A.; Tung, S.; Gerber, A.; Wang, D.; Huang, Y.; Cecen, V.; Kotov, N.A. Biomimetic Solid-State Zn(2+) Electrolyte for Corrugated Structural Batteries. ACS Nano 2019, 13, 1107-1115.

18. Zhu, J.; Cao, W.; Yue, M.; Hou, Y.; Han, J.; Yang, M. Strong and Stiff Aramid Nanofiber/Carbon Nanotube Nanocomposites. ACS Nano 2015, 9, 2489-2501. [CrossRef] [PubMed]

19. Fan, J.; Wang, J.; Shi, Z.; Yu, S.; Yin, J. Kevlar nanofiber-functionalized multiwalled carbon nanotubes for polymer reinforcement. Mater. Chem. Phys. 2013, 141, 861-868. [CrossRef]

20. Fan, J.; Shi, Z.; Tian, M.; Yin, J. Graphene-aramid nanofiber nanocomposite paper with high mechanical and electrical performance. RSC Adv. 2013, 3, 17664-17667. [CrossRef]

21. Kwon, S.R.; Harris, J.; Zhou, T.; Loufakis, D.; Boyd, J.G.; Lutkenhaus, J.L. Mechanically Strong Graphene/Aramid Nanofiber Composite Electrodes for Structural Energy and Power. ACS Nano 2017, 11, 6682-6690. [CrossRef] [PubMed] 
22. Kwon, S.R.; Elinski, M.B.; Batteas, J.D.; Lutkenhaus, J.L. Robust and Flexible Aramid Nanofiber/Graphene Layer-by-Layer Electrodes. ACS Appl. Mater. Interfaces 2017, 9, 17125-17135. [CrossRef]

23. Shah, S.A.; Kulhanek, D.; Sun, W.; Zhao, X.; Yu, S.; Parviz, D.; Lutkenhaus, J.L.; Green, M.J. Aramid nanofiber-reinforced three-dimensional graphene hydrogels for supercapacitor electrodes. J. Colloid Interface Sci. 2020, 560, 581-588. [CrossRef] [PubMed]

24. Wu, K.; Wang, J.; Liu, D.; Lei, C.; Liu, D.; Lei, W.; Fu, Q. Highly Thermoconductive, Thermostable, and Super-Flexible Film by Engineering 1D Rigid Rod-Like Aramid Nanofiber/2D Boron Nitride Nanosheets. Adv. Mater. 2020, 32, e1906939. [CrossRef] [PubMed]

25. Lin, M.; Li, Y.; Xu, K.; Ou, Y.; Su, L.; Feng, X.; Li, J.; Qi, H.; Liu, D. Thermally conductive nanostructured, aramid dielectric composite films with boron nitride nanosheets. Compos. Sci. Technol. 2019, 175, 85-91. [CrossRef]

26. Jung, J.; Sodano, H.A. High strength epoxy nanocomposites reinforced by epoxy functionalized aramid nanofibers. Polymer 2020, 195, 122438. [CrossRef]

27. Zhao, Y.; Li, X.; Shen, J.; Gao, C.; Van der Bruggen, B. The potential of Kevlar aramid nanofiber composite membranes. J. Mater. Chem. A 2020, 8, 7548-7568. [CrossRef]

28. Yang, B.; Wang, L.; Zhang, M.; Li, W.; Zhou, Q.; Zhong, L. Advanced separators based on aramid nanofiber (ANF) membranes for lithium-ion batteries: A review of recent progress. J. Mater. Chem. A 2021, 9, 12923-12946. [CrossRef]

29. Zhang, B.; Wang, W.; Tian, M.; Ning, N.; Zhang, L. Preparation of aramid nanofiber and its application in polymer reinforcement: A review. Eur. Polym. J. 2020, 139, 109996. [CrossRef]

30. Park, S.-A.; Eom, Y.; Jeon, H.; Koo, J.M.; Kim, T.; Jeon, J.; Park, M.J.; Hwang, S.Y.; Kim, B.-S.; Oh, D.X.; et al. Aramid Nanofiber Templated In Situ SNAr Polymerization for Maximizing the Performance of All-Organic Nanocomposites. ACS Macro Lett. 2020, 9,558-564. [CrossRef]

31. Lee, J.U.; Park, B.; Kim, B.-S.; Bae, D.-R.; Lee, W. Electrophoretic deposition of aramid nanofibers on carbon fibers for highly enhanced interfacial adhesion at low content. Compos. Part A Appl. Sci. Manuf. 2016, 84, 482-489. [CrossRef]

32. Park, B.; Lee, W.; Lee, E.; Min, S.H.; Kim, B.S. Highly tunable interfacial adhesion of glass fiber by hybrid multilayers of graphene oxide and aramid nanofiber. ACS Appl. Mater. Interfaces 2015, 7, 3329-3334. [CrossRef]

33. Zhu, C.; Zhang, J.; Xu, J.; Yin, X.; Wu, J.; Chen, S.; Zhu, Z.; Wang, L.; Wang, H. Aramid nanofibers/polyphenylene sulfide nonwoven composite separator fabricated through a facile papermaking method for lithium ion battery. J. Membr. Sci. 2019, 588, 117169. [CrossRef]

34. Liu, L.; Lyu, J.; Mo, J.; Yan, H.; Xu, L.; Peng, P.; Li, J.; Jiang, B.; Chu, L.; Li, M. Comprehensively-upgraded polymer electrolytes by multifunctional aramid nanofibers for stable all-solid-state Li-ion batteries. Nano Energy 2020, 69, 104398. [CrossRef]

35. Li, Y.; Ren, G.; Zhang, Z.; Teng, C.; Wu, Y.; Lu, X.; Zhu, Y.; Jiang, L. A strong and highly flexible aramid nanofibers/PEDOT:PSS film for all-solid-state supercapacitors with superior cycling stability. J. Mater. Chem. A 2016, 4, 17324-17332. [CrossRef]

36. Yin, Q.; Jia, H.; Mohamed, A.; Ji, Q.; Hong, L. Highly flexible and mechanically strong polyaniline nanostructure @ aramid nanofiber films for free-standing supercapacitor electrodes. Nanoscale 2020, 12, 5507-5520. [CrossRef]

37. Bo, S.; Ren, W.; Lei, C.; Xie, Y.; Cai, Y.; Wang, S.; Gao, J.; Ni, Q.; Yao, J. Flexible and porous cellulose aerogels /zeolitic imidazolate framework (ZIF-8) hybrids for adsorption removal of Cr(IV) from water. J. Solid State Chem. 2018, 262, 135-141. [CrossRef]

38. Vivas, E.L.; Lee, S.; Cho, K. Brushite-infused polyacrylonitrile nanofiber adsorbent for strontium removal from water. J. Environ. Manag. 2020, 270, 110837. [CrossRef]

39. Wang, J.; Yu, W.; Graham, N.J.D.; Jiang, L. Evaluation of a novel polyamide-polyethylenimine nanofiltration membrane for wastewater treatment: Removal of $\mathrm{Cu}^{2+}$ ions. Chem. Eng. J. 2020, 392, 123769. [CrossRef]

40. Zong, L.; Yang, Y.; Yang, H.; Wu, X. Shapeable Aerogels of Metal-Organic-Frameworks Supported by Aramid Nanofibrils for Efficient Adsorption and Interception. ACS Appl. Mater. Interfaces 2020, 12, 7295-7301. [CrossRef] [PubMed]

41. Cheng, Z.; Bai, Z.; Dai, Y.; Luo, L.; Liu, X. Benzimidazole-containing aramid nanofiber for naked-eye detection of heavy metal ions. Analyst 2018, 143, 5225-5233. [CrossRef] [PubMed]

42. Yuan, Y.; Li, J.; Liu, Y.; Chen, T.; Lin, J. Layer-by-layer self-assembly of aramid nanofibers on nonwoven fabric for liquid filtration. Polym. Compos. 2018, 39, 2411-2419. [CrossRef]

43. Lv, L.; Han, X.; Zong, L.; Li, M.; You, J.; Wu, X.; Li, C. Biomimetic Hybridization of Kevlar into Silk Fibroin: Nanofibrous Strategy for Improved Mechanic Properties of Flexible Composites and Filtration Membranes. ACS Nano 2017, 11, 8178-8184. [CrossRef] [PubMed]

44. Li, Y.; Yuan, S.; Zhou, C.; Zhao, Y.; Van der Bruggen, B. A high flux organic solvent nanofiltration membrane from Kevlar aramid nanofibers with in situ incorporation of microspheres. J. Mater. Chem. A 2018, 6, 22987-22997. [CrossRef]

45. Sun, S.; Yue, Y.; Huang, X.; Meng, D. Protein adsorption on blood-contact membranes. J. Membr. Sci. 2003, 222, 3-18. [CrossRef]

46. Ran, F.; Niu, X.; Song, H.; Cheng, C.S.; Zhao, W.; Nie, S.; Wang, L.; Yang, A.; Sun, S.; Zhao, C. Toward a highly hemocompatible membrane for blood purification via a physical blend of miscible comb-like amphiphilic copolymers. Biomater. Sci. 2014, 2, 538-547. [CrossRef]

47. Peng, Z.; Yang, Y.; Luo, J.; Nie, C.; Ma, L.; Cheng, C.; Zhao, C. Nanofibrous polymeric beads from aramid fibers for efficient bilirubin removal. Biomater. Sci. 2016, 4, 1392-1401. [CrossRef]

48. Nie, C.; Yang, Y.; Peng, Z.; Cheng, C.; Ma, L.; Zhao, C. Aramid nanofiber as an emerging nanofibrous modifier to enhance ultrafiltration and biological performances of polymeric membranes. J. Membr. Sci. 2017, 528, 251-263. [CrossRef] 
49. Lei, D.; Ko, T.H.; Yang, J.-Y.; Li, X.-D.; Seo, M.-K.; Kim, H.-Y.; Kim, B.-S. Flexible high-temperature sheet-type electric heaters using m-aramid/functionalized MWCNTs hybrid nanofiber composites. Compos. Part B Eng. 2019, 166, 41-47. [CrossRef]

50. Ma, Z.; Kang, S.; Ma, J.; Shao, L.; Wei, A.; Liang, C.; Gu, J.; Yang, B.; Dong, D.; Wei, L.; et al. High-Performance and RapidResponse Electrical Heaters Based on Ultraflexible, Heat-Resistant, and Mechanically Strong Aramid Nanofiber/Ag Nanowire Nanocomposite Papers. ACS Nano 2019, 13, 7578-7590. [CrossRef]

51. Hu, P.; Lyu, J.; Fu, C.; Gong, W.B.; Liao, J.; Lu, W.; Chen, Y.; Zhang, X. Multifunctional Aramid Nanofiber/Carbon Nanotube Hybrid Aerogel Films. ACS Nano 2020, 14, 688-697. [CrossRef]

52. Lyu, J.; Zhao, X.; Hou, X.; Zhang, Y.; Li, T.; Yan, Y. Electromagnetic interference shielding based on a high strength polyanilinearamid nanocomposite. Compos. Sci. Technol. 2017, 149, 159-165. [CrossRef]

53. Lei, C.; Zhang, Y.; Liu, D.; Wu, K.; Fu, Q. Metal-Level Robust, Folding Endurance, and Highly Temperature-Stable MXene-Based Film with Engineered Aramid Nanofiber for Extreme-Condition Electromagnetic Interference Shielding Applications. ACS Appl. Mater. Interfaces 2020, 12, 26485-26495. [CrossRef]

54. Liu, Y.; Zhang, K.; Mo, Y.; Zhu, L.; Yu, B.; Chen, F.; Fu, Q. Hydrated aramid nanofiber network enhanced flexible expanded graphite films towards high EMI shielding and thermal properties. Compos. Sci. Technol. 2018, 168, 28-37. [CrossRef]

55. Moore, A.L.; Shi, L. Emerging challenges and materials for thermal management of electronics. Mater. Today 2014, 17, 163-174. [CrossRef]

56. Si, L.; Lu, Z.; Yao, C.; Ma, Q.; Zhao, Y.; Wang, Y.; Wang, D.; Jin, Z. Nacre-like nanocomposite film with excellent dielectric insulation properties and mechanical strength based on montmorillonite nanosheet and aramid nanofiber. J. Mater. Sci. 2020, 55, 5948-5960. [CrossRef]

57. Rahman, M.M.; Puthirath, A.B.; Adumbumkulath, A.; Tsafack, T.; Robatjazi, H.; Barnes, M.; Wang, Z.; Kommandur, S.; Susarla, S.; Sajadi, S.M.; et al. Fiber Reinforced Layered Dielectric Nanocomposite. Adv. Funct. Mater. 2019, 29, 1900056. [CrossRef]

58. Zeng, F.; Chen, X.; Xiao, G.; Li, H.; Xia, S.; Wang, J. A Bioinspired Ultratough Multifunctional Mica-Based Nanopaper with 3D Aramid Nanofiber Framework as an Electrical Insulating Material. ACS Nano 2020, 14, 611-619. [CrossRef]

59. Liu, Z.; Lyu, J.; Fang, D.; Zhang, X. Nanofibrous Kevlar Aerogel Threads for Thermal Insulation in Harsh Environments. ACS Nano 2019, 13, 5703-5711. [CrossRef]

60. Lyu, J.; Liu, Z.; Wu, X.; Li, G.; Fang, D.; Zhang, X. Nanofibrous Kevlar Aerogel Films and Their Phase-Change Composites for Highly Efficient Infrared Stealth. ACS Nano 2019, 13, 2236-2245. [CrossRef]

61. Ma, T.; Zhao, Y.; Ruan, K.; Liu, X.; Zhang, J.; Guo, Y.; Yang, X.; Kong, J.; Gu, J. Highly Thermal Conductivities, Excellent Mechanical Robustness and Flexibility, and Outstanding Thermal Stabilities of Aramid Nanofiber Composite Papers with Nacre-Mimetic Layered Structures. ACS Appl. Mater. Interfaces 2020, 12, 1677-1686. [CrossRef] [PubMed]

62. Xiao, G.; Di, J.; Li, H.; Wang, J. Highly thermally conductive, ductile biomimetic boron nitride/aramid nanofiber composite film. Compos. Sci. Technol. 2020, 189, 108021. [CrossRef]

63. Han, X.; Lv, L.; Yu, D.; Wu, X.; Li, C. Conductive Core-Shell Aramid Nanofibrils: Compromising Conductivity with Mechanical Robustness for Organic Wearable Sensing. ACS Appl. Mater. Interfaces 2019, 11, 3466-3473. [CrossRef] [PubMed] 